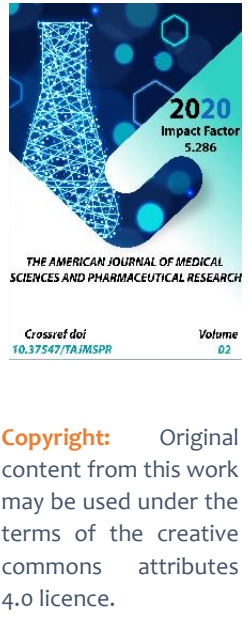

\title{
Effective Metods Of Treatment For Chronic Heart Failure In Elderli Women
}

Adizova D.R.

Bukhara State Medical Institute, Uzbekistan

\section{ABSTRACT}

To study the effectiveness of teaching "self-care" and "self-control" in elderly and senile patients with chronic heart failure. The study included 107 patients with chronic heart failure. The training program was attended by 54 patients who made up the study group. 53 untrained patients made up the control group. These sessions were conducted with patients for 7 days, 1 hour per day. To assess the effectiveness of the training program, adherence to treatment was assessed using the Morisky-Green scale and the quality of life was assessed using the Minnesota questionnaire on the quality of life of patients. Results. During 1 year of follow-up, feedback was interrupted with 17 patients $(15,8 \%)$ due to various reasons. Out of 90 subjects of observation, only 6 patients $(6,7 \%)$ died due to the deterioration of their condition and the development of associated conditions. The assessment of the number of visits by patients to family polyclinics showed a generally satisfactory level of clinical examination in the study group - the average rate of planned visits was 3,2. In the control group, the average number of visits was 2,5 per year. There was a statistically significantly lower number of unplanned visits to the study group compared to patients from the control group. As a result, there was a significant decrease in the number of unplanned visits in the intervention group as a whole. Conclusion. The program of training elderly and senile patients on the aspects of self-medication and self-control in chronic heart failure is effective in improving the control of their adherence to therapy and the prognosis of the disease.

\section{KEYWORDS}

Chronic heart failure; training; self-care; self-control; elderly age. 


\section{INTRODUCTION}

Despite the significant advances in modern medicine in the treatment of cardiovascular diseases (CVD), the prevalence of chronic heart failure (CHF) is not only not decreasing, but is also growing steadily $[1,2]$. At the beginning of the 21st century, concepts such as "self-care" (self-management) and self-monitoring have become an integral part of treatment programs for patients with various chronic infectious diseases, including $\mathrm{CHF}[3,4]$. Various types of outpatient management programs for patients with $\mathrm{CHF}$ are becoming increasingly relevant for modern medicine. The main goal of these programs is secondary prevention, that is, the prevention of further deterioration of the patient's condition.

The programs include a number of measures to increase information support for patients with $\mathrm{CHF}$ and their relatives regarding their health status, ways to improve the quality of life, selfhelp methods and self-control of their health status $[5,6,7,8]$. The main task of selfmedication and self-control in CHF is to maintain the clinical stability of patients. This concept includes the absence of clinical signs of circulatory stagnation in the form of orthopnea, peripheral edema of cardiac origin, rapid weight gain, the need to take diuretics, and increased pressure in the jugular veins $[9,10]$.

Studies have shown that patients with FC IV CHF who successfully control symptoms of congestion have the best survival rates, which are approximately equal to those of patients with FC III $[11,12]$. In this regard, it is relevant to develop new patient management programs or adapt existing programs with their further implementation in order to improve the quality of life of patients and reduce mortality.

\section{PURPOSE OF THE STUDY}

To assess the effectiveness of teaching "selftreatment" and "self-control" in elderly and senile patients with $\mathrm{CHF}$ using innovative technologies and identifying factors that affect their effectiveness.

\section{MATERIAL AND RESEARCH METHODS}

The study included 107 patients with CHF FC IIIII who were admitted to the hospital. The average age of the patients was $71.4 \pm 7.7$ years. All patients received inpatient treatment in a cardiology or therapy department for a duration of 10 to 12 days. Drug therapy included the basic treatment of CHF with the inclusion of drugs from the group of ACE inhibitors, betablockers, diuretics, if necessary, and cardiac glycosides in various combinations with supplementation in the form of drugs from other groups, depending on the individual characteristics of the course of $\mathrm{CHF}$ in patients (National recommendations of VNOK And OSSN for the diagnosis and treatment of CHF (third revision))

During this time, all patients were trained in the aspects of self-treatment and self-control in the form of individual or group sessions. Taking into account the peculiarities of the age, mentality, lifestyle and marital status of patients in this sample, the content of the classes was adapted taking into account the specifics of each. Table 1 details the topics of the patient education sessions and their content. The content of the patient education 
course and the lesson plan were drawn up by the authors.

The training program was attended by 54 patients who made up the main group. 53 patients who did not undergo training made up the control group (Table 2). These sessions were conducted with patients for 7 days, 1 hour per day. At the same time, the patients were given handouts in the form of booklets and brochures. When passing the training, it was required to keep a notebook and briefly record the content of the classes.

Table 1.

Topic titles and content

\begin{tabular}{|c|c|c|}
\hline № & Lesson topic & Contents \\
\hline 1 & $\begin{array}{l}\text { General information } \\
\text { about CHF }\end{array}$ & $\begin{array}{l}\text { Simplified explanation of the mechanisms of CHF development } \\
\text { to the patient. }\end{array}$ \\
\hline 2 & Body weight control & $\begin{array}{c}\text { Explaining to the patient about the need for daily weighing in } \\
\text { the morning (before breakfast in the same clothes and on the } \\
\text { same scales) and the need to report an increase in body weight } \\
\text { by } 1.5 \mathrm{~kg} \text { to the doctor, provided that there are no changes in } \\
\text { the diet. }\end{array}$ \\
\hline 3 & Diet & $\begin{array}{l}\text { Educating patients about the knowledge and skills to recognize } \\
\text { low and high salt diets. Clarification of the need to keep a } \\
\text { journal with daily records of food intake in order to } \\
\text { subsequently correct the diet. }\end{array}$ \\
\hline 4 & CHF symptoms & $\begin{array}{l}\text { Teaching patients to identify the most significant symptoms of } \\
\text { CHF: weight gain, shortness of breath, decreased exercise } \\
\text { tolerance, edema, increased fatigue, severity in the right } \\
\text { hypochondrium. Explaining to the patient the need for timely } \\
\text { notification of the attending physician about the symptoms of } \\
\text { increased CHF. }\end{array}$ \\
\hline 5 & Drug therapy & $\begin{array}{l}\text { Establishing all prescribed medications. A simplified explanation } \\
\text { and discussion of the need to prescribe each of them and the } \\
\text { side effects associated with their use. }\end{array}$ \\
\hline
\end{tabular}




\begin{tabular}{|c|c|c|}
\hline 6 & Drug therapy & $\begin{array}{c}\text { Clarification and discussion of adequate doses of drugs and the } \\
\text { need to take them exactly as prescribed by the doctor. Keeping } \\
\text { a special individual diary of medication intake. }\end{array}$ \\
\hline 7 & $\begin{array}{r}\text { Monitoring physical } \\
\text { activity }\end{array}$ & $\begin{array}{r}\text { Teaching patients to establish their own level of tolerated } \\
\text { physical activity in the form of the number of steps or distance } \\
\text { in meters that he is able to overcome without exacerbating the } \\
\text { symptoms of CHF. }\end{array}$ \\
\hline
\end{tabular}

To assess the effectiveness of the training program, adherence to treatment was assessed according to the Morisky-Green scale and the quality of life was assessed using the Minnesota CHF Quality of Life Questionnaire (MLHFQ).

After the patients were discharged from the hospital, their control was carried out through unstructured telephone contacts, interactive contact through mobile messengers. For the analysis, the data obtained at the beginning and at the end of the study were used. As the first point of observation, a case of hospitalization for decompensation of $\mathrm{CHF}$ was chosen, and the second point was a routine examination after 1 year. At the same time, the number of visits to the doctor in accordance with the individual plans of dispensary observation (IPDO) in the family polyclinic or rural medical station, cases of calls of the emergency medical station teams (EMST) and the number of unscheduled visits to the doctor due to the increase in CHF symptoms were taken into account. The study did not take into account the attendance of patients in medical organizations outside the IPDO, not associated with decompensation of $\mathrm{CHF}$, including those caused by the need to prescribe prescriptions for drugs under the additional drug provision program.

The data obtained during the study were subjected to statistical processing on a Pentium-IV personal computer using the Microsoft Office Excel-2012 software package, including the use of built-in statistical processing functions.

\section{RESULTS}

During 1 year of follow-up, feedback was interrupted with 17 patients (15.8\%), 8 patients in the main group and 9 patients in the control group, due to various reasons (refusal to participate, territorial factor, lack of communication means). In this regard, the results of the study were analyzed in the remaining 90 patients. Analysis of the distribution of patients by FC CHF after 1 year of follow-up showed that only 6 patients (6.7\%) out of 90 subjects died due to deterioration of their condition and the development of associated conditions (Fig. 1).

The highest proportion of deaths occurred in elderly patients $(n=5)$, among elderly patients - 1. In all deceased patients, CHF corresponded to $\mathrm{FC} 3$. At the same time, the number of cases of the transition from $\mathrm{FC} 2 \mathrm{CHF}$ to $\mathrm{FC} 3 \mathrm{CHF}$ in 
the two groups differed significantly, in especially in the elderly group. So, among elderly patients undergoing training, 1 case of FC transition to a higher level was observed, while among untrained patients, the number of cases of FC change to a higher level was 2. Among elderly patients undergoing training, there were 2 deaths and 2 cases of FC 2 change on FC 3. Among the untrained, there were 3 deaths and 4 cases of changes in the FC of CHF.

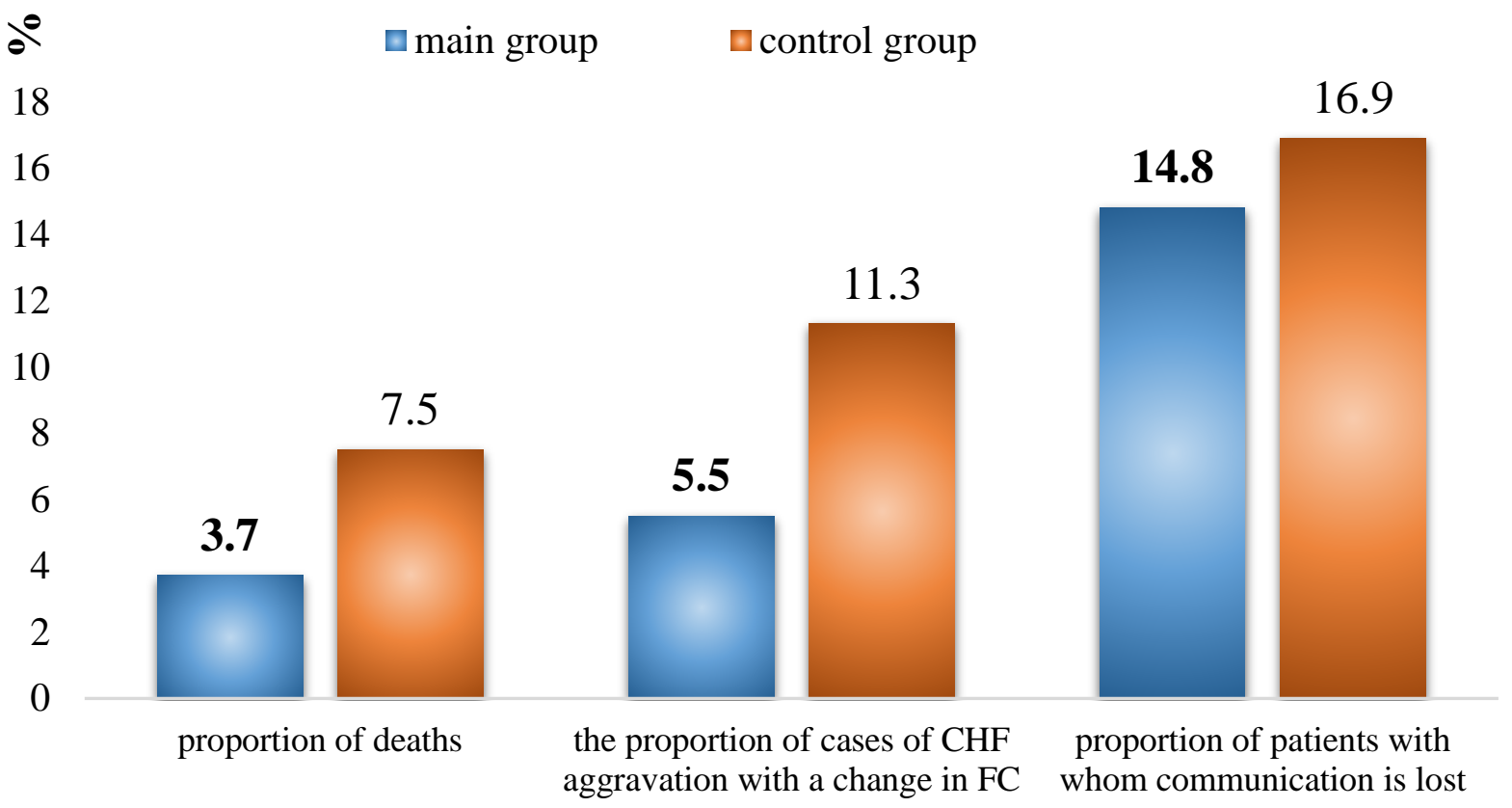

Figure 1. Comparative analysis of the effectiveness of training in patients in the study groups.

The observation results showed that, in comparison with the control group $(n=40)$, in the main group $(n=44)$ during 1 year of follow- up, there was a significantly lower number of elderly patients who were hospitalized and applied to the EMST (Fig. 2). 
80

$\square$ main group $\square$ control group

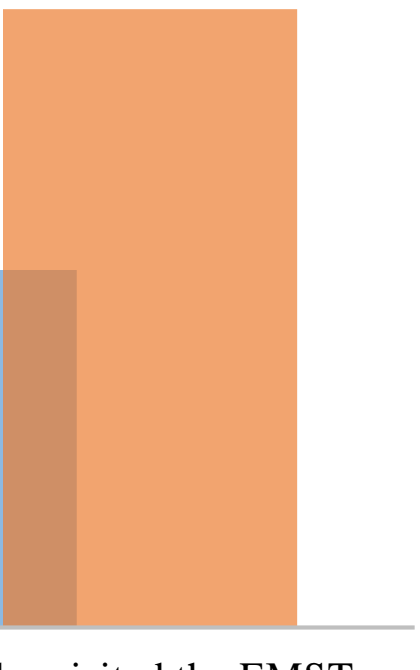

$\%$ of hospitalized in hospital

47.7

50

47.5

47.7

40

30

20

10

s

\section{8}

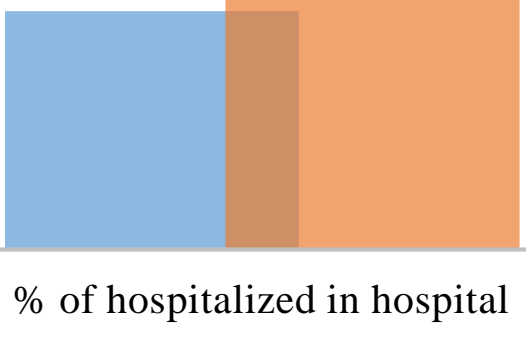

$\%$ of patients who visited the EMST

Figure 2. Percentage of elderly patients admitted to hospital and admitted to the EMST for CHF within 1 year.

The assessment of the number of visits to patients with CHF according to the IPDO in the family polyclinic showed a generally satisfactory level of clinical examination in the main group - on average, the indicator of planned visits was 3.2 (according to the standard, the number of visits for CHF should be 4). In the control group, the average number of visits was 2.5 per year (Fig. 3). 
3.5

3

2.5

2

1.5

1

0.5

0
3.2

$\square$ main group $\quad \square$ control group

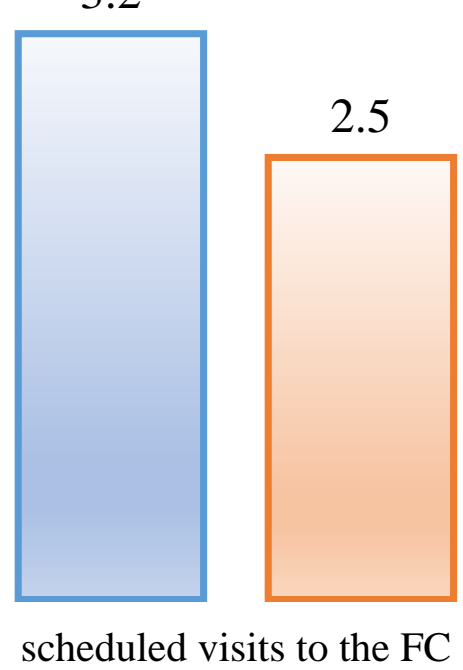

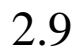

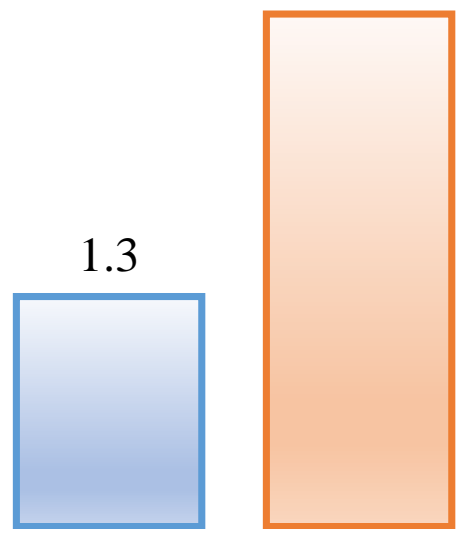

unscheduled visits to FC

Figure 3. The number of visits to the family polyclinic (for 1 elderly patient) within 1 year.

At the same time, there was a significant variability in the number of unplanned patient visits due to the increase in CHF symptoms. There was a statistically significant less number of unplanned visits to the main group compared to patients from the control group. As a result, there was a significant decrease in the number of unplanned visits in the intervention group as a whole.

Dynamics of the indicators of the quality of life of patients during the one-year follow-up was found that the indicator significantly improved in the main group, while in the control group it underwent insignificant changes or negative dynamics were observed.

\section{DISCUSSION}

The need to improve the system of management and control of treatment of patients with $\mathrm{CHF}$ in the older age group is due to the fact that the highest rate of readmission among patients was noted in the group over 65 , where it is $40-57 \%[13,14]$. At the same time, the frequency of early readmission to hospital (within 3-6 months after discharge from hospital) among the elderly reaches 25-45\% $[15,16]$. All of the above causes high financial costs for the treatment of CHF. In particular, in the USA, where the number of hospitalizations due to $\mathrm{CHF}$ is about 1 million per year, the costs amount to $1-2 \%$ of all health care costs $[6,9]$.

After the participation of patients with $\mathrm{CHF}$ in the training program, some significant differences were revealed between the compared groups in the frequency of reaching secondary points, manifested in a decrease in the need of patients for emergency services, a decrease in the number of unscheduled visits 
to the joint venture for decompensation of CHF. In the course of the study, it was determined that in the control group among women, significantly worse results of dispensary observation and treatment were revealed compared to the main group. At the same time, the participation of women in the training program reduced the need for hospitalizations for decompensation of $\mathrm{CHF}$ during 1 year of observation and treatment.

In a study by foreign authors [10], it was demonstrated that the gender of elderly patients is an important factor influencing the effectiveness of the health school, since the use of training in the main group in women turned out to be a less effective means of secondary prevention of CHF than in men. All of the above can serve as evidence of the effectiveness of teaching elderly patients with CHF to aspects of self-medication and selfcontrol.

\section{CONCLUSION}

Thus, the program of teaching elderly and senile patients about the aspects of selftreatment and self-control in chronic heart failure is effective in improving the control of their adherence to therapy and the prognosis of the disease. At the same time, the proposed technique is economically inexpensive and is easily feasible in modern realities thanks to communication means. In this regard, the proposed training program for patients with chronic heart failure can be adapted and introduced into the practice of both outpatient institutions of primary care and in the practice of inpatient institutions to improve the therapy of this pathology.

\section{REFERENCES}

1. Adamo $M$, Lombardi $C M$, Metra $M$. November 2019 at a glance. Chronic and acute heart failure: from epidemiology to treatment. European Journal of Heart Failure. Wiley; 2019;21(11):1297-8.

2. Vinogradova NG. City Center for the Treatment of Chronic Heart Failure: the organiza-tion of work and the effectiveness of treatment of patients with chronic heart failure. Kardiologiia. APO Society of Specialists in Heart Failure; 2019;59(2S):319.

3. Garganeeva AA, Bauehr VA, Borel' KN. Pandemiya XXI veka: hronicheskaya serdechnaya nedostatochnost' - bremya sovremennogo obshchestva [The pandemic of the twenty - first century: chronic heart failure is a burden on modern society. Epidemiological aspects (literature review)]. Epidemiologicheskie aspekty (obzor literatury). Sibirskij medicinskij zhurnal. 2014;3:8-13. Russian.

4. Mareev VY, Ageev FT, Arutyunov GP. Nacional'nye rekomendacii OSSN, RKO i RNMOT po diagnostike i lecheniyu HSN [National guidelines PRAS cardiology and internal medicine on the diagnosis and treatment of chronic heart failure]. Serdechnaya nedostatochnost'. 2013;7:3801. Russian.

5. Svetyj LI, Lopuhova VA, Tarasenko IV. Analiz osnovnyh prichin dekompensacii bol'-nyh HSN na dogospital'nom ehtape lecheniya [Analysis of the main causes of decompensation of pain CNS at the prehospital stage of treatment]. ZHurnal nauchnyh statej Zdorov'e i obrazovanie $v$ XXI veke. 2014;4:229-30. Russian. 
6. Stein G.Y., Kremer A., Shochat T. et al. The diversity of heart failure in a hospitalized population: the role of age // J Card Fail. 2012. - №18. - P. 645-653.

7. Takada T., Sakata Y., Miyata S. et al. Impact of elevated heart rate on clinical outcomes in patients with heart failure with reduced and preserved ejection fraction -A report from the CHART-2 Study // Eur. J. Heart Fail. - 2014. - №16. - P. 309-316.

8. Adizova DR, Ashurova NG, Khalilova FA, Djuraeva NO. Rational approach to standard therapy// Central Asian Journal of Pediatrics. - 2019. - 2 (2), - P. 49-53.

9. Tseng C.H. Clinical features of heart failure hospitalization in younger and elderly patients in Taiwan // European Journal of Clinical Investigation. - 2010. -№41(6). - P. 597-604.

10. Hwang S.L., Liao W.C., Huang T.Y. Predictors of quality of life in patients with heart failure // Jpn. J. Nurs Sci. - 2014. - №11(4). - P. 290298.

11. Lam C.S.P., Carson P.E., Anand I.S., Sex differences in clinical characteristics and outcomes in elderly patients with heart failure and preserved ejection fraction: The I-PRESERVE Trial // Circ. Heart Fail. - 2012. №5. - P. 571-578.

12. Lazzarini V., Mentz R.J., Fiuzat M. et al. Heart failure in elderly patients: distinctive features and unresolved issues // Eur J Heart Fail. - 2013. - №15. - P. 717-723.

13. Shimokawa H., Miura M., Nochioka K. et al. Heart failure as a general pandemic in Asia // Eur. J. Heart Fail. - 2015. - №17. - P. 884-894.

14. Shreyaswi Sathyanath M. Proportion of Depression Among the Elderly Population in
A Rural Health Care Setting // J. Clin. Diagn Res. - 2014. - №8(1). - P. 137-139.

15. Bots S.H., Groepenhoff F., Eikendal A.L.M. et al. Adverse Drug Reactions to GuidelineRecommended Heart Failure Drugs in Women // JACC: Heart Failure. - 2019. №7(3). - P. 258-266.

16. Byszewski A., Azad N., Molnar F.J. et al. Clinical pathways: adherence issues in complex older female patients with heart failure (HF) // Arch GerontolGeriatr. - 2010. №50. - P. 165-170. 